\title{
El radioyente castellanoleonés de retransmisiones deportivas de la radio generalista. Estudio de cinco variables: sus preferencias, fidelización, satisfacción, motivaciones y medio de escucha ${ }^{1}$
}

The Castilian-Leonese listener of sport broadcasting in generalistic radio. A study of five variables: their preferences, loyalty, satisfaction, motivations and mean of listening

\author{
Francisco Javier HERRERO GUTIÉRREZ \\ Universidad de Salamanca \\ javiherrero82@usal.es
}

Hilario José ROMERO BEJARANO Universidad de Sevilla (España)

Recibido: 3 de marzo de 2014 Aceptado y Publicado: 25 de abril de 2014

\begin{abstract}
Resumen
La presente investigación se enmarca dentro del ámbito de la comunicación deportiva en España y, en concreto, del medio radiofónico. En este estudio se realiza una aproximación a cinco variables relacionadas con el radioyente castellanoleonés de retransmisiones deportivas en la radio generalista española. Dichas variables son: sus preferencias, fidelización, satisfacción, motivaciones y medio de escucha. Los resultados fueron obtenidos a partir de la realización de una encuesta -en octubre de 2011- aplicada a una muestra de 200 personas de Castilla y León que son radioyentes de alguno de los siguientes cinco programas: "Carrusel Deportivo", de la Cadena SER; «Tiempo de Juego», de la COPE; «La Liga en Punto» («El Mirador de la Liga» hasta la temporada 2010/11), de Punto Radio; «Radioestadio», de Onda Cero; $y$ «Tablero Deportivo» de Radio Nacional de España.
\end{abstract}

\section{Abstract}

${ }^{1}$ Este artículo es fruto del trabajo sobre una 
This research is part of the field of the sport communication in Spain and, specifically, of the radio media. This study is an approach to five variables related to the Castilian-Leonese listener of sport broadcasting in the spanish generalistic radio. These variables are: their preferences, loyalty, satisfaction, motivations and mean of listening. The results were obtained from a survey -conducted in October 2011- applied to a sample of 200 people from Castile and Leon who are listeners of any of the following five programs: "Carrusel Deportivo» (SER); «Tiempo de Juego» (COPE); «La Liga en Punto» («El Mirador de la Liga» until the season 2010/11), (Punto Radio); "Radioestadio» (Onda Cero); and "Tablero Deportivo» (Radio Nacional de España).

Palabras Clave: comunicación deportiva, radio deportiva, retransmisión deportiva, Castilla y León, radioyente

Key Words: sport communication, sport radio, sport broadcasting, Castile and Leon, listener

\section{Introducción}

Desde hace varios años, ya se puede afirmar que "si nos acercamos a cualquier medio de comunicación, pronto apreciaremos la importancia que en éste tiene el deporte" (Hernández, 2003: 11) porque ese deporte "ha creado entre sus practicantes y espectadores ansias de sentir, vivir y soñar. Se ha convertido en una necesidad social [...]" (Castañón, 2004: 9). Pero aunque la comunicación deportiva tiene una gran acogida desde el ámbito profesional y suscita un gran interés para el receptor desde el punto de vista del espectáculo (, 2010b: 3) no han sido demasiadas las investigaciones realizadas sobre este campo de la Comunicación desde perspectivas científicas: "...el periodismo deportivo no es un objeto de estudio frecuente..." (Gozalo, 2002: 12). Al menos, sí se puede decir que, en lo que a la comunicación deportiva respecta, los ámbitos profesional y académico no están equiparados en un mismo nivel de producción. Por suerte para la investigación de la información deportiva, parece que cada vez con más frecuencia se producen estudios científicos sobre esta derivación de la Comunicación, que permiten abordar esta especialización a través de una perspectiva más académica.

Este artículo recoge una investigación sobre un aspecto muy concreto de la comunicación deportiva. En este estudio se presenta una investigación realizada sobre el medio radiofónico y la visión que tienen los radioyentes castellanoleoneses sobre cinco programas de la radio española generalista que contienen retransmisiones deportivas. A lo largo del presente estudio, se analizan cinco variables: saber cuáles son los programas que tienen mayor éxito, la fidelización del oyente respecto al programa que escucha, su grado de satisfacción, los motivos que le llevan a escuchar un determinado programa y, por último, conocer cuál es el sistema de escucha elegido para oír dicho programa.

\section{Marco teórico}

Facultad de Ciencias de la Información - Universidad de La Laguna

Avenida César Manrique, s/n; Campus de Guajara

38071 La Laguna, Tenerife (Islas Canarias - España) 


\subsection{La información deportiva}

En pleno siglo XXI, es difícil poner en duda que la información deportiva en España tiene un peso más que importante dentro de la sociedad. Los principales medios de comunicación, y los datos de audiencia de éstos, así lo ilustran. Y sin pretender hacer un análisis exhaustivo de cada medio, se pueden reseñar diversos aspectos con los que destacar la importancia del deporte dentro de los medios de comunicación, entendiéndolo como un espectáculo de entre la división estipulada en su día por Cagigal (1981) entre deporte-práctica y deporteespectáculo. Dichos aspectos que hacen del deporte un espectáculo quedan reflejados en datos como:

- En televisión, los mejores datos de audiencia de las cadenas más relevantes de España son conseguidos gracias a la emisión de pruebas deportivas. Las propias cadenas de televisión realizan fuertes inversiones para adquirir derechos televisivos de especialidades deportivas. Respecto a 2011, año en el que se encuadra la encuesta: "En el ránking de los espacios más vistos, hay un predominio claro del género deportivo por encima de cualquier otro (Selección española de fútbol, Champions League, Liga española, etc.)" (FórmulaTV.com/TVE, 2012). Respecto a ese mismo año 2011, si se tomase como muestra el programa más visto de cada uno de los 12 meses del año, se obtiene que en 10 de los 12 meses dicho programa es una competición deportiva -de esos 10: nueve fueron un partido de fútbol y uno un Gran Premio de Fórmula 1.

- En prensa escrita, España es un país en el que existen varios diarios deportivos de tirada nacional. Entre ellos se encuentra el diario Marca, que se sitúa entre los de mayor tirada y difusión del país, según los datos de la OJD. Además, según los datos del EGM (resumen : febrero 2011 - noviembre 2011), este periódico es el más leído de España, por delante del resto de diarios, incluidos los de información general.

- En radio, en las principales emisoras generalistas españolas, gran parte de su audiencia está compuesta por radioyentes de temática deportiva. Teniendo en cuenta el último EGM del año 2011, algunos datos muestran que:

a-) En la Cadena SER, los programas «Carrusel Deportivo» y «El Larguero» están entre los cinco programas más escuchados de la emisora.

b-) Lo mismo sucede en la COPE con sus programas deportivos «Tiempo de Juego» y «El Partido de las 12». Además, «Tiempo de Juego», en su edición dominical es el programa más escuchado de toda la emisora. 
c-) En Onda Cero sucede prácticamente lo mismo que en las emisoras SER y COPE; los dos programas deportivos de Onda Cero, «Radioestadio» y "Al primer toque» se encuentran entre los seis más escuchados de la emisora y «Radioestadio», el programa deportivo de retransmisiones deportivas, es el tercer más escuchado de Onda Cero.

d-) En Radio Nacional de España (RNE), el programa de retransmisiones deportivas «Tablero Deportivo» es el tercero más escuchado de la emisora.

Hay que tener en cuenta, además, que en España existe una radio de temática exclusivamente deportiva: Radio Marca, lo que define la importancia de este género específico del periodismo (Alcoba, 2005: 165).

- En Internet: según la OJDinteractiva, y referido a datos de acceso (nacional e internacional), en la clasificación de Navegadores Únicos (datos de diciembre de 2011 ), de las más de 400 web que mide la OJDinteractiva, www.marca.com se sitúa en tercer lugar, sólo superada por softonic.com y MSN. Además, www.marca.com ocuparía el primer lugar si se tuviera en cuenta el número de páginas; y el segundo lugar si se tuviera en cuenta el número de visitas. Por lo tanto, la versión web de Marca, una WWW de temática exclusivamente deportiva, sirve de nuevo para ilustrar el seguimiento que el deporte tiene en España; en este caso, también en Internet.

Todo ello no es más que una pequeña muestra para ilustrar que la comunicación deportiva en España es una de las especializaciones de mayor seguimiento y, quizás, debido a que el deporte es "un soporte privilegiado de la información masiva: es una fuente inagotable de noticias. En el mundo del deporte cada día hay algo que reseñar" (Medina, 1995: 74).

\subsubsection{La radio deportiva en España}

Si el marco teórico se ciñe al medio objeto de estudio de esta investigación, se puede decir que el interés de la radio por el deporte, a nivel internacional se produce a comienzos de la segunda década del siglo XX cuando "la perfección tecnológica de las comunicaciones alcanzó a los medios de comunicación y la radio se interesa por el deporte, sobre todo una vez que son posibles las retransmisiones deportivas" (Alcoba, 1993: 65). Internacionalmente, "es difícil saber cuándo empiezan exactamente las retransmisiones deportivas radiofónicas y quién las inicia" (Blanco, 2002: 23) aunque uno de los primeros deportes en ser retransmitido fue el boxeo (ALCOBA, 1993: 65): un combate narrado por la KDKA puede ser considerado como una narración pionera (BLANCO, 2002: 23) si bien "en Estados Unidos la primera prueba experimental la llevó a cabo en 1920 la radio del Texas A \& M College. Por lo visto, se trataba de la retransmisión de un partido de fútbol americano universitario" (Blanco, 2002: 
23). Eso ocurrió en Estados Unidos pero ese boom norteamericano se extendió al resto del mundo: la radio deportiva comenzó a triunfar y, con ella, las retransmisiones deportivas radiofónicas.

En España, la que se puede denominar como radio deportiva se instauró paulatinamente: en 1926 se retransmitió un combate de boxeo entre Uzcudun y Spalla (Díaz, 1992: 14); y en mayo 1927 se retransmitió un Zaragoza-Real Madrid a través de Unión Radio (Malvar, 2005: XVII; Blanco, 2002: 23); un partido que se pudo escuchar por las emisoras de "Madrid, Barcelona, Bilbao, Sevilla, Salamanca y San Sebastián. Es la primera documentación que se tiene de una retransmisión de un partido de fútbol" (Pons, en Balsebre, 1999: 116). Inicialmente en España, aparte del fútbol y el boxeo, también se retransmitieron otros deportes, como la pelota a mano, la cesta punta, las carreras de caballos o la lucha libre (Malvar, 2005: XVII). Así hasta llegar a los años 50 "cuando surge con toda intensidad el deporte en la radio. Sobre todo el fútbol" (Malvar, 2005: XVII), un deporte que, no sólo en la radio sino también en términos mediáticos globales, genera "mediante la atención informativa de los medios de comunicación, un interés en los aficionados a este deporte, dotándole de una visibilidad mediática y posicionado su imagen de marca" (Olabe, 2009: 122). Desde entonces, radio y fútbol siempre se han complementado: "El fútbol y la radio han llegado a una perfecta simbiosis. Se complementan a la perfección. Después de tantos años de coexistencia feliz, es impensable una jornada futbolística sin la retransmisión de los partidos" (Pons en Balsebre, 1999: 115).

Con el fútbol a la cabeza, las retransmisiones deportivas han seguido creciendo en España. $\mathrm{Y}$, posteriormente, con el paso de los años, se fueron complementando especialmente con la aparición de programas deportivos radiofónicos nocturnos, que tuvieron una gran acogida y que, a día de hoy, tienen un gran éxito. Hasta llegar al punto actual: "Las principales emisoras, y las más escuchadas, ofrecen a sus oyentes durante los siete días de la semana, programas deportivos a nivel nacional y programas locales deportivos en diferentes franjas horarias, según la emisora" (, 2009: 47). Aunque, como se viene indicando, la programación deportiva está presente en diversas franjas horarias, y ha adquirido un peso específico en la programación radiofónica nocturna, especialmente el mayor número de horas de radio deportiva está concentrado en los fines de semana y gracias a programas que vienen respaldados por las audiencias, como se ha ilustrado en el epígrafe anterior.

Además, en España, la importancia del deporte en el medio radiofónico se puede llevar tanto desde un nivel nacional (, 2009: 48-49), como autonómico, como demuestra Sierra (2010) en un estudio sobre la oferta de programación en las radios autonómicas de titularidad pública en España: "Uno de los contenidos más demandados por la audiencia son los que están relacionado con los deportes. En especial el fútbol y los deportes relacionados con el motor: fórmula1 y motociclismo. De ahí que la información de tipo deportivo sea cada vez más demandada por la audiencia. Este fenómeno social, no ha pasado desapercibido para los 
programadores, que ven en los programas deportivos una oportunidad para atraer oyentes (incrementar audiencia) y por otro lado atraer a posibles anunciantes" (Sierra, 2010: 373).

Se ha llegado incluso a un punto en el que la radio "continúa en su imparable marcha de acaparar espacios y programas deportivos, hasta el punto de arrinconar a programas de solera cuando debe retransmitir competiciones deportivas" (Alcoba, 2005: 165) muy probablemente porque "las retransmisiones deportivas son mucho más que eso: se han convertido en uno de los mayores atractivos del medio televisivo y radiofónico desde que empezaron a ser posibles" (Blanco, 2002: 21) a la vez que "representan una de las mayores fuentes de ingresos en las empresas radiofónicas y televisivas" (Blanco, 2002: 21). Para concluir este epígrafe, se puede decir que la radio deportiva tiene tal presencia, "sobre todo durante los fines de semana, que requiere un tratamiento aparte para poder dar cuenta con rigor de la realidad radiofónica" (Gutiérrez et. al., 2003).

\subsection{La credibilidad radiofónica respaldada por el oyente}

Dentro de todo este entramado que se viene comentando, a fin de cuentas, el éxito de la comunicación deportiva viene justificado por el respaldo que encuentra entre el público. Es por eso por lo que se justifica la realización de un estudio focalizado en conocer algo mejor a ese público -su opinión- y es ésa la temática que se trata en este estudio. No en vano, "lo más importante en una retransmisión es la persona a quien va dirigida: el oyente" (Pons en Balsebre, 1999: 115).

Hay que tener en cuenta que "la transmisión de una información creíble es uno de los mayores retos al que diariamente se enfrentan los periodistas" (Perona, 2009: 368) y el medio analizado, la radio, es un medio considerado por muchos autores como el más creíble (Faus, 1974, Balsebre, 1994; y Pousa, en Rodero, 2005) y "sigue siendo el medio de comunicación que inspira más confianza en la mayoría de la población española según las últimas encuestas de opinión y percepción del público" (Pacheco, 2009: 100) quizás por ser "el primer gran medio extendido entre la población al que se puede tener acceso de forma gratuita constantemente, más allá de la compra de un receptor apropiado para ello" ( et. al., 2009: 969). Llevado a la información radiofónica, ésta siempre ha tenido un público fiel, incluso en los momentos aparentemente más difíciles, como con la llegada de la televisión: "Quienes pensaron que la televisión terminaría con la radio tuvieron una escasa visión de futuro, ya que este medio de comunicación no sólo resistió el envite, sino que ha aumentado sus posibilidades" (Alcoba, 2005: 165). De hecho, en lo que a las retransmisiones deportivas se refiere, radio y televisión han alcanzado un punto de equilibrio y no son pocos los radioyentes que también son, al mismo tiempo, televidentes; o viceversa: el que se podría denominar como 'radiovidente' (, 2010a). En términos generales, se puede decir que en 
España, la tradición ampara la idea de que la radio deportiva es fiel a su oyente y el oyente lo agradece devolviéndole esa misma fidelidad.

\section{Objetivo e hipótesis}

El objetivo es ahondar sobre ciertas variables que permitan conocer con más precisión ciertas características de los radioyentes castellanoleoneses que escuchan alguno de los cinco programas deportivos pre-seleccionados en la muestra. Para ello, se parte de una serie de cinco hipótesis:

3.1-) De entre los cinco programas pre-seleccionados, el programa más escuchado es «Carrusel Deportivo» (Cadena SER), seguido por «Tiempo de Juego» (Cadena COPE).

3.2-) Se espera una alta fidelización a los programas que los radioyentes escuchan, superior a los cinco años de seguimiento.

3.3-) Los radioyentes muestran un alto grado de satisfacción con el programa escuchado y, al menos, se espera una nota de 7 sobre 10.

3.4-) No existe una motivación concreta que permita determinar las causas por las que un radioyente escucha un programa y no otro.

3.5-) Los principales sistemas de recepción son los tradicionales: transistor / aparato de radio / cadena de música / minicadena de música / similar.

\section{Metodología}

La investigación está basada en la realización de una encuesta con el objetivo de "recoger información acerca de la frecuencia, distribución y correlación entre ciertas variables de una población. En el ámbito de las Ciencias Sociales quizá el ejemplo más representativo de encuesta son los estudios de opinión" (Igartua, 2006: 232). La encuesta se realizó una vez diseñado un cuestionario, herramienta que permitió "recoger información a partir de la formulación de preguntas" (Igartua, 2006: 232). En el presente caso, después de conocer el sexo, la edad y la provincia de la persona encuestada, cinco de las preguntas planteadas estaban dirigidas a conocer las respuestas a los cinco ítems examinados en esta 
investigación, relacionados con la opinión que los radioyentes castellanoleoneses de retransmisiones deportivas que se emiten en la radio generalista tienen sobre estos programas:

a-) Conocer qué programa era el que el radioyente escuchaba -encuesta realizada entre el 3 de octubre de 2011 y el 21 de octubre de 2011-, de entre las siguientes cinco opciones de programas (más otras dos opciones: no sabe cuál escucha y NS/NC):

- «Carrusel Deportivo», de la Cadena SER

- «Tiempo de juego», de la Cadena COPE

- «La Liga en Punto» («El Mirador de la Liga» hasta la temporada 2010/11), de Punto Radio

- «Radioestadio», de Onda Cero

- «Tablero Deportivo», de Radio Nacional de España (RNE)

- No sé cuál escucho

- NS/NC

b-) Fidelización: para tratar el apartado de fidelización, la pregunta propuesta fue: “¿Desde cuándo escucha ese programa de forma habitual?" El encuestador tenía que cuadrar las respuestas entre alguna de las siguientes alternativas:

- Hace menos de 6 de meses

- Entre 6 meses y menos de 1 año

- Entre 1 año y menos de 2

- Entre 2 años y menos de 5

- 5 años o más 
c-) Grado de satisfacción: para conocer el grado de satisfacción, la cuestión propuesta fue: "Respecto a ese programa que usted escucha habitualmente ¿cuál sería su grado de satisfacción en una escala del 0 al 10? (siendo 0 negativo, 5 aceptable y 10 muy positivo/inmejorable)".

d-) Motivos: por último, para conocer los motivos por los que el receptor escucha un determinado programa, la pregunta realizada fue: “¿Cuáles son los motivos por los que suele escuchar ese programa? Señalar todas las respuestas que sean necesarias". Y las posibles alternativas en las que el encuestador podía englobar las respuestas obtenidas eran las siguientes:

- Porque siempre he escuchado este programa y no me apetece cambiar

- Porque nunca cambio el dial

- Porque es el único que tiene cobertura donde vivo

- Porque es el que mejor se oye en la localidad que vivo

- Porque es el más asentado desde el punto de vista histórico

- Por los presentadores y locutores

- Por todo el equipo que trabaja en esa emisora

- Por la ideología de la emisora

- Porque el programa que escucho me parece mejor que los otros

- Porque el programa que escucho me gusta más que los otros

- Porque en mi casa siempre se ha escuchado esta emisora

- Porque en mi casa siempre se ha escuchado este programa 
- Porque este programa defiende los intereses de mi equipo

- Porque es el más humorístico, más allá del propio deporte

- Porque a los integrantes del programa los considero parte de mi familia

- Porque prefiero escuchar retransmisiones nacionales y no locales

- Por un determinado director / animador / locutor

$-N S / N C$

- Por otro motivo. Indicar

e-) Medio de escucha: para conocer esta variable, la pregunta que se realizó fue la siguiente: "¿A través de qué medio escucha habitualmente ese programa? (señalar sólo una opción, la que más utilice)". Y las posibles alternativas en las que el encuestador podía incluir la respuesta obtenida eran:

- Transistor / Aparato de radio / Cadena / Minicadena / Similar

- Aparato de música del coche

- Televisión / TDT

- Internet

- Teléfono móvil

- Podcast

- Otro. Indicar 


\subsection{Población, muestra y realización de la encuesta}

En segundo lugar, se diseñó una muestra: "Por lo general, en Comunicación y en las Ciencias Sociales se encuesta a muestras que son extraídas de poblaciones. El universo o población es el conjunto de elementos objeto de estudio, de los cuales se desea obtener cierta información. Una muestra es un subconjunto de una población" (Igartua, 2006: 314). En el presente caso, el universo estaba conformado por los radioyentes de Castilla y León que escuchasen alguno de los cinco siguientes programas que contienen retransmisiones deportivas radiofónicas en las emisoras generalistas previamente seleccionadas:

- «Carrusel deportivo», de la Cadena SER

- «Tiempo de Juego», de la COPE

- «La Liga en Punto», de Punto Radio

- «Radioestadio», de Onda Cero

- «Tablero Deportivo», de Radio Nacional de España.

Como se aprecia, el medio de comunicación 'objeto de estudio' es la radio y, en concreto, la radio con temática deportiva (radio deportiva) y, más específicamente, los programas que contienen retransmisiones deportivas radiofónicas. En cualquier caso, el objeto de estudio se realizó escogiendo de antemano las cinco emisoras generalistas que tienen un mayor alcance nacional en su sistema analógico de emisión y, probablemente, como indican algunos autores, "las cinco cadenas de radio nacionales más importantes del país" (Ortiz et. al., 2009: 146): SER, COPE, RNE, Onda Cero y Punto Radio. A partir de la población, dicha muestra -"un subconjunto de la población" (SALKIND, 1998: 96)- estuvo compuesta por 200 individuos y fue seleccionada mediante muestreo aleatorio estratificado, según tres criterios:

- Sexo: Hombre / Mujer

- Grupos de edad: Entre 14 y 34 años / Entre 35 y 54 años / 55 años o más 
- Región: Oeste (León, Zamora y Salamanca) / Centro (Palencia, Valladolid y Ávila) / Este (Burgos, Soria y Segovia)

Sobre dicha muestra estratificada se aplicaría el mencionado cuestionario para conocer diversos interrogantes; entre ellos, para tratar los cinco ítems que se presentan en este estudio. La encuesta se haría telefónicamente, sistema que "ha aumentado considerablemente durante los últimos años gracias al creciente desarrollo tecnológico" (Igartua, 2006: pp. 289-290). Finalmente, la encuesta fue realizada, entre el 3 de octubre de 2011 y el 21 de octubre de 2011, por Gather Estudios a través de un sistema CATI (plataforma Gather Precision) sobre la mencionada muestra de 200 personas seleccionadas mediante muestreo aleatorio estratificado.

\section{Resultados}

A partir de la encuesta realizada, en cuanto al primer ítem analizado se refiere, la frecuencia de programas escuchados de entre las posibles alternativas ofrecidas se obtuvo que el programa más escuchado por los radioyentes castellanoleoneses era "Carrusel Deportivo" de la Cadena SER (106 encuestados escogieron esta opción; 53\% del total de encuestados) seguido por «Tiempo de Juego» de la COPE (52 encuestados; 26\%). En tercer lugar, el programa «Radioestadio», de Onda Cero (20 encuestados, 10\%). El cuarto más escuchado resultó ser el programa de Punto Radio «La Liga en Punto» («El Mirador de la Liga» hasta la temporada 2010/11) (10 encuestados; 5\%) y por último: «Tablero Deportivo» de Radio Nacional de España (8 encuestados, 4\%). Un pequeño porcentaje no sabía qué programa escuchaba (4 encuestados; $2 \%$ ). De forma más específica, se presenta la siguiente tabla (Tabla 1) en la que se tienen en cuenta las variables: grupos de edad, sexo, regiones y programas: 
Tabla 1: programas escuchados según variables grupos de edad/sexo/región

\begin{tabular}{|c|c|c|c|c|c|c|c|c|c|c|}
\hline \multirow[b]{2}{*}{$\begin{array}{l}\text { Grupos } \\
\text { de } \\
\text { edad }\end{array}$} & \multirow[b]{2}{*}{ Sexo } & & & \multicolumn{6}{|c|}{ Programa escuchado } & \multirow[b]{2}{*}{ Total } \\
\hline & & & & $\begin{array}{c}\text { Carrusel } \\
\text { Deportivo } \\
\text { (Cadena SER) } \\
\end{array}$ & $\begin{array}{c}\text { Tiempo de } \\
\text { Juego } \\
\text { (COPE) }\end{array}$ & $\begin{array}{c}\text { La Liga en } \\
\text { Punto (EI } \\
\text { Mirador de la } \\
\text { Liga hasta la } \\
\text { temporada } \\
2010 / 11 \text { ) } \\
\text { (Punto Radio) }\end{array}$ & $\begin{array}{l}\text { Radioestadio } \\
\text { (Onda Cero) }\end{array}$ & $\begin{array}{c}\text { Tablero } \\
\text { Deportivo } \\
\text { (Radio } \\
\text { Nacional de } \\
\text { España) } \\
\end{array}$ & $\begin{array}{l}\text { No sé cuál } \\
\text { escucho }\end{array}$ & \\
\hline \multirow{8}{*}{$\begin{array}{l}\text { Entre } \\
14 \text { y } 34\end{array}$} & Hombre & Región & Oeste & $35,7 \%$ & $64,3 \%$ & & & & & $100,0 \%$ \\
\hline & & & Centro & $58,3 \%$ & $8,3 \%$ & & $33,3 \%$ & & & $100,0 \%$ \\
\hline & & & Este & $60,0 \%$ & & $40,0 \%$ & & & & $100,0 \%$ \\
\hline & & Total & & $50,0 \%$ & $27,8 \%$ & $11,1 \%$ & $11,1 \%$ & & & $100,0 \%$ \\
\hline & Mujer & Región & Oeste & $42,9 \%$ & & & $28,6 \%$ & & $28,6 \%$ & $100,0 \%$ \\
\hline & & & Centro & $100,0 \%$ & & & & & & $100,0 \%$ \\
\hline & & & Este & & $50,0 \%$ & $50,0 \%$ & & & & $100,0 \%$ \\
\hline & & Total & & $46,7 \%$ & $13,3 \%$ & $13,3 \%$ & $13,3 \%$ & & $13,3 \%$ & $100,0 \%$ \\
\hline \multirow{8}{*}{\begin{tabular}{|l} 
Entre \\
35 y 54
\end{tabular}} & Hombre & Región & Oeste & $45,8 \%$ & $25,0 \%$ & $8,3 \%$ & $12,5 \%$ & $8,3 \%$ & & $100,0 \%$ \\
\hline & & & Centro & $45,0 \%$ & $40,0 \%$ & & & $5,0 \%$ & $10,0 \%$ & $100,0 \%$ \\
\hline & & & Este & $14,3 \%$ & $71,4 \%$ & & $14,3 \%$ & & & $100,0 \%$ \\
\hline & & Total & & $37,9 \%$ & $41,4 \%$ & $3,4 \%$ & $8,6 \%$ & $5,2 \%$ & $3,4 \%$ & $100,0 \%$ \\
\hline & Mujer & Región & Oeste & $60,0 \%$ & $40,0 \%$ & & & & & $100,0 \%$ \\
\hline & & & Centro & $90,0 \%$ & & $10,0 \%$ & & & & $100,0 \%$ \\
\hline & & & Este & $71,4 \%$ & $14,3 \%$ & $14,3 \%$ & & & & $100,0 \%$ \\
\hline & & Total & & $74,1 \%$ & $18,5 \%$ & $7,4 \%$ & & & & $100,0 \%$ \\
\hline \multirow{8}{*}{$\begin{array}{l}550 \\
\text { más }\end{array}$} & Hombre & Región & Oeste & $31,3 \%$ & $31,3 \%$ & & $18,8 \%$ & $18,8 \%$ & & $100,0 \%$ \\
\hline & & & Centro & $62,5 \%$ & $12,5 \%$ & & $18,8 \%$ & $6,3 \%$ & & $100,0 \%$ \\
\hline & & & Este & $41,7 \%$ & $25,0 \%$ & & $25,0 \%$ & $8,3 \%$ & & $100,0 \%$ \\
\hline & & Total & & $45,5 \%$ & $22,7 \%$ & & $20,5 \%$ & $11,4 \%$ & & $100,0 \%$ \\
\hline & Mujer & Región & Oeste & $90,0 \%$ & $10,0 \%$ & & & & & $100,0 \%$ \\
\hline & & & Centro & $100,0 \%$ & & & & & & $100,0 \%$ \\
\hline & & & Este & $100,0 \%$ & & & & & & $100,0 \%$ \\
\hline & & Total & & $95,0 \%$ & $5,0 \%$ & & & & & $100,0 \%$ \\
\hline
\end{tabular}

Fuente: Encuesta realizada por Gather Estudios para este estudio / Tabla: elaboración propia.

La segunda hipótesis trataba de averiguar la fidelización de los oyentes encuestados y los resultados obtenidos fueron los siguientes (Tabla 2): 
Tabla 2: Estudio de la fidelización según la variable temporal

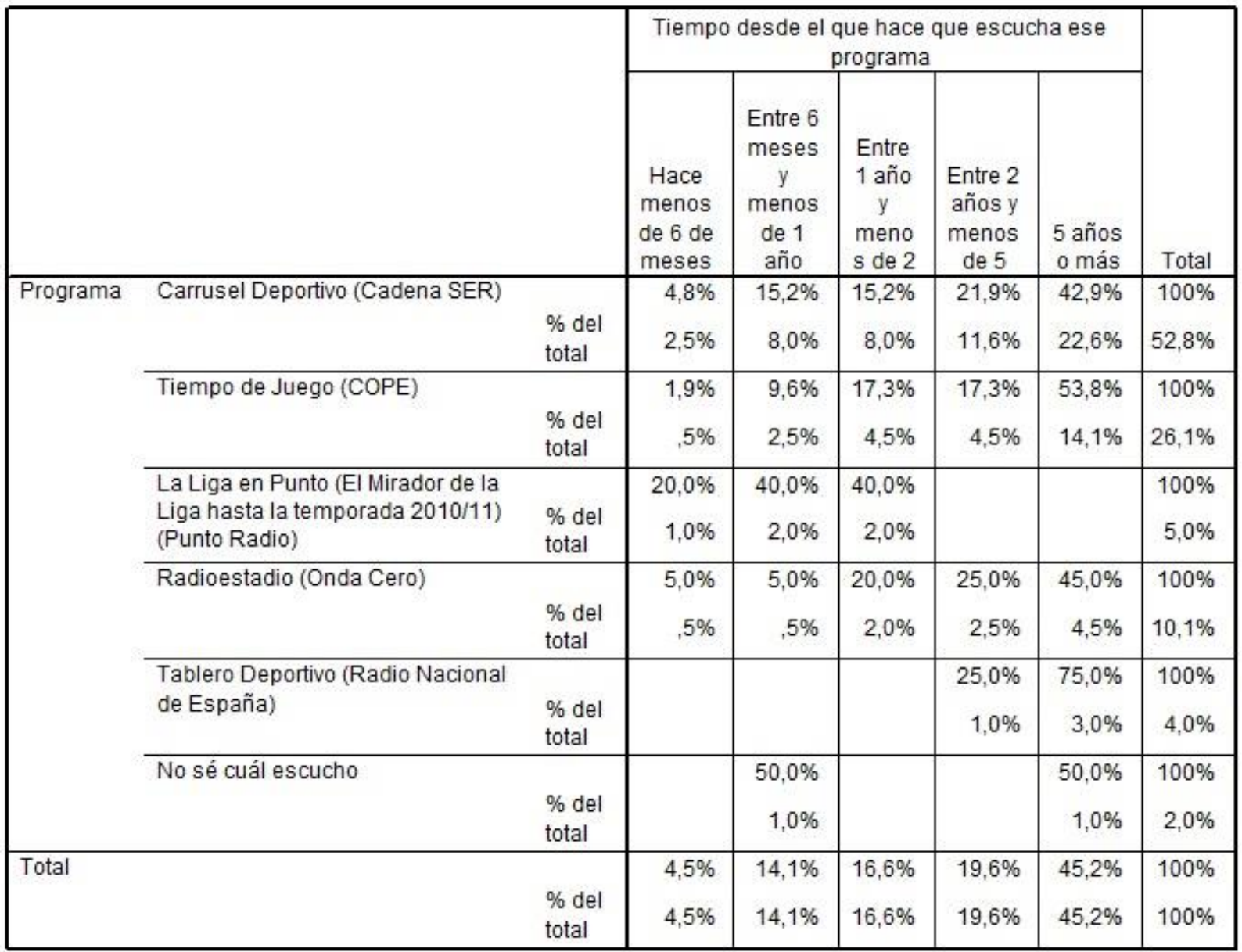

Fuente: Encuesta realizada por Gather Estudios para este estudio / Tabla: elaboración propia.

En cuanto a la hipótesis 3 , que trata de medir el grado de satisfacción respecto al programa escuchado, se obtienen los siguientes datos (Tabla 3): 
Tabla 3: Nota otorgada por los radioyentes

\begin{tabular}{|c|c|c|c|c|c|c|c|c|c|}
\hline & & \multicolumn{7}{|c|}{ Nota otorgada en una escala de 0 a 10} & \multirow[b]{2}{*}{ Total } \\
\hline & & 4 & 5 & 6 & 7 & 8 & 9 & 10 & \\
\hline \multirow[t]{6}{*}{ Programa } & $\begin{array}{l}\text { Carrusel Deportivo (Cadena } \\
\text { SER) }\end{array}$ & $2,8 \%$ & $9,4 \%$ & $19,8 \%$ & $25,5 \%$ & $23,6 \%$ & $14,2 \%$ & $4,7 \%$ & $100 \%$ \\
\hline & Tiempo de Juego (COPE) & $3,8 \%$ & $9,6 \%$ & $28,8 \%$ & $19,2 \%$ & $13,5 \%$ & $21,2 \%$ & $3,8 \%$ & $100 \%$ \\
\hline & $\begin{array}{l}\text { La Liga en Punto (El Mirador de } \\
\text { la Liga hasta la temporada } \\
\text { 2010/11) (Punto Radio) }\end{array}$ & & $20,0 \%$ & $30,0 \%$ & $20,0 \%$ & $30,0 \%$ & & & $100 \%$ \\
\hline & Radioestadio (Onda Cero) & & & $25,0 \%$ & $15,0 \%$ & $35,0 \%$ & $25,0 \%$ & & $100 \%$ \\
\hline & $\begin{array}{l}\text { Tablero Deportivo (Radio } \\
\text { Nacional de España) }\end{array}$ & & $12,5 \%$ & $25,0 \%$ & $25,0 \%$ & $25,0 \%$ & $12,5 \%$ & & $100 \%$ \\
\hline & No sé cuál escucho & & & $50,0 \%$ & $25,0 \%$ & $25,0 \%$ & & & $100 \%$ \\
\hline Total & & $2,5 \%$ & $9,0 \%$ & $24,0 \%$ & $22,5 \%$ & $22,5 \%$ & $16,0 \%$ & $3,5 \%$ & $100 \%$ \\
\hline
\end{tabular}

Fuente: Encuesta realizada por Gather Estudios para este estudio / Tabla: elaboración propia.

De forma general a todos ellos, se obtuvo una media genérica de 7,16 puntos, en una escala del 0 al 10. La nota máxima otorgada a algunos de los programas por distintos encuestados fue de 10 puntos sobre 10 mientras que ningún encuestado otorgó a ningún programa una nota inferior a 4 puntos.

En lo que a las motivaciones se refiere (hipótesis 4), los resultados obtenidos fueron los siguientes (Tabla 4): 
Tabla 4: Motivos de los oyentes para escuchar un determinado programa

\begin{tabular}{|c|c|c|}
\hline MOTIVO & $\begin{array}{c}\text { Número de veces } \\
\text { que se escogió } \\
\text { esta opción (máx. } \\
200)\end{array}$ & $\begin{array}{l}\text { Porcentaje } \\
\quad(\%)\end{array}$ \\
\hline $\begin{array}{l}\text { Porque siempre he escuchado este } \\
\text { programa y no me apetece cambiar }\end{array}$ & 78 & $39 \%$ \\
\hline Porque nunca cambio el dial & 19 & $9,5 \%$ \\
\hline $\begin{array}{l}\text { Porque es el único que tiene cobertura } \\
\text { donde vivo }\end{array}$ & 3 & $1,5 \%$ \\
\hline $\begin{array}{l}\text { Porque es el que mejor se oye en la } \\
\text { localidad que vivo }\end{array}$ & 5 & $2,5 \%$ \\
\hline $\begin{array}{l}\text { Porque es el más asentado desde el punto } \\
\text { de vista histórico }\end{array}$ & 4 & $2 \%$ \\
\hline Por los presentadores y locutores & 92 & $46 \%$ \\
\hline $\begin{array}{c}\text { Por todo el equipo que trabaja en esa } \\
\text { emisora }\end{array}$ & 31 & $15,5 \%$ \\
\hline Por la ideología de la emisora & 13 & $6,5 \%$ \\
\hline $\begin{array}{l}\text { Porque el programa que escucho me parece } \\
\text { mejor que los otros }\end{array}$ & 35 & $17,5 \%$ \\
\hline $\begin{array}{l}\text { Porque el programa que escucho me gusta } \\
\text { más que los otros }\end{array}$ & 42 & $21 \%$ \\
\hline $\begin{array}{l}\text { Porque en mi casa siempre se ha } \\
\text { escuchado esta emisora }\end{array}$ & 12 & $6 \%$ \\
\hline $\begin{array}{l}\text { Porque en mi casa siempre se ha } \\
\text { escuchado este programa }\end{array}$ & 8 & $4 \%$ \\
\hline $\begin{array}{l}\text { Porque este programa defiende los } \\
\text { intereses de mi equipo }\end{array}$ & 1 & $0,5 \%$ \\
\hline $\begin{array}{l}\text { Porque es el más humorístico, más allá del } \\
\text { propio deporte }\end{array}$ & 5 & $2,5 \%$ \\
\hline $\begin{array}{l}\text { Porque a los integrantes del programa los } \\
\text { considero parte de mi familia }\end{array}$ & 2 & $1 \%$ \\
\hline $\begin{array}{l}\text { Porque prefiero escuchar retransmisiones } \\
\text { nacionales y no locales }\end{array}$ & 2 & $1 \%$ \\
\hline $\begin{array}{l}\text { Por un determinado director / animador / } \\
\text { locutor }\end{array}$ & 8 & $4 \%$ \\
\hline $\mathrm{NS} / \mathrm{NC}$ & 4 & $2,5 \%$ \\
\hline
\end{tabular}




\begin{tabular}{|l|l|l|} 
Por otro motivo. Indicar & 27 & $13,5 \%$ \\
\hline
\end{tabular}

Fuente: Encuesta realizada por Gather Estudios para este estudio / Tabla: elaboración propia.

Cuando se indicó otro motivo, las razones que ofrecieron los encuestados fueron las siguientes:

- Por todo en general (1)

- Por ser la primera emisora que sintoniza (1)

- Mejoró mucho con el cambio Cadena SER / Cadena COPE (2)

- Por cobertura (2)

- Por estar informado (1)

- Es de los que se escucha bien por Internet (1)

- Es el que sintonizan en el lugar donde me encuentro (1)

- Es lo que se sintoniza a esa hora (1)

- Por la ausencia de publicidad (1)

- Por los buenos comentaristas (1)

- Abarca muchos deportes y no se centra sólo en el fútbol (1)

- Por estar algo informado en deportes (1)

- Porque son unos profesionales (1)

- Por cambiar (1) 
Por último, en lo que a la quinta hipótesis se refiere, el medio escogido por los radioyentes de Castilla y León para escuchar un determinado programa -de los cinco analizados-, los resultados indicaron que los medios preferentes eran:

- Transistor / Aparato de radio / Cadena / Minicadena / Similar (el 50,3\% escogió esta opción)

- Aparato de música del coche (el 31,7\% escogió está opción)

En menor medida, la tercera opción elegida para escuchar estos programas fue la televisión / TDT $(9,5 \%)$ y sin apenas incidencia: el teléfono móvil $(2,5 \%)$ e Internet (1\%). Cuando el encuestado indicó otro medio de escucha distinto a los propuestos, en las respuestas obtenidas no se identificó realmente ninguna respuesta que no pudiese ser encuadrada en cualquier de las respuestas anteriores -sólo se encontraron reiteraciones.

\section{Discusión de los resultados}

Si se tiene en cuenta la primera hipótesis planteada, obtenemos que el programa más escuchado, en términos globales en Castilla y León, es «Carrusel Deportivo», con un 53\% de oyentes. El programa de la Cadena SER es uno de los más asentados desde el punto de vista histórico y es, por ejemplo, también el más escuchado a nivel nacional según los datos que periódicamente arroja la AIMC a través del EGM. Asimismo, según la investigación realizada, el segundo programa más escuchado sería «Tiempo de Juego», con un $26 \%$ del total de encuestados. La remodelación llevada a cabo en la sección de deportes de la Cadena COPE durante el verano de 2010, muy probablemente, benefició a este programa y ayudó a mejorar sus datos de audiencia-respaldado a nivel nacional también por los datos del EGM. En tercer lugar se situaría «Radioestadio», con un 10\%. En cuarto lugar, «La Liga en Punto», de la emisora Punto Radio y, con un porcentaje similar a ésta aunque algo inferior, estaría el programa «Tablero Deportivo», de Radio Nacional de España.

En cuanto a la segunda hipótesis, de forma general se obtiene una alta fidelización a este tipo de programas. Si se tienen en cuenta los resultados globales, en más de un $45 \%$ de los casos, los radioyentes castellanoleoneses siguen un determinado programa desde hace 5 años o más. El caso más notable es el de «Tablero Deportivo», en el que el $75 \%$ de sus oyentes siguen dicho programa desde hace 5 años o más. En el lado opuesto se situaría el programa de Punto Radio ya que, según los datos del estudio, todos sus oyentes escuchan dicho programa desde hace menos de 2 años. Se observa un claro contraste entre estas dos emisoras: según el estudio, todos los oyentes de «La Liga en Punto» («El Mirador de la Liga» 
hasta la temporada 2010/11) escuchan el programa desde hace menos de 2 años mientras que todos los radioyentes de «Tablero Deportivo» (RNE) escuchan dicho programa desde hace 2 o más años.

Resultan especialmente curiosos los datos de «Carrusel Deportivo», de la Cadena SER, y «Tiempo de Juego», de la COPE. Los cambios producidos en las direcciones de estos dos programas durante el periodo 2010-2011 podían hacer prever un mayor número de oyentes 'nuevos' en ambas emisoras y, sin embargo, esto no sucede y son pequeños porcentajes de radioyentes los que escuchan dichos programas desde hace menos de 1 año. Ambos programas -tanto el de la SER como el de la COPE- presentan una tendencia que dibuja un mayor número de oyentes consolidados o afines al programa desde hace varios años; lo mismo que sucede en el programa «Radioestadio», de Onda Cero (Gráfico 1):

Gráfico 1: Tendencia (\%) de oyentes según los años de fidelización

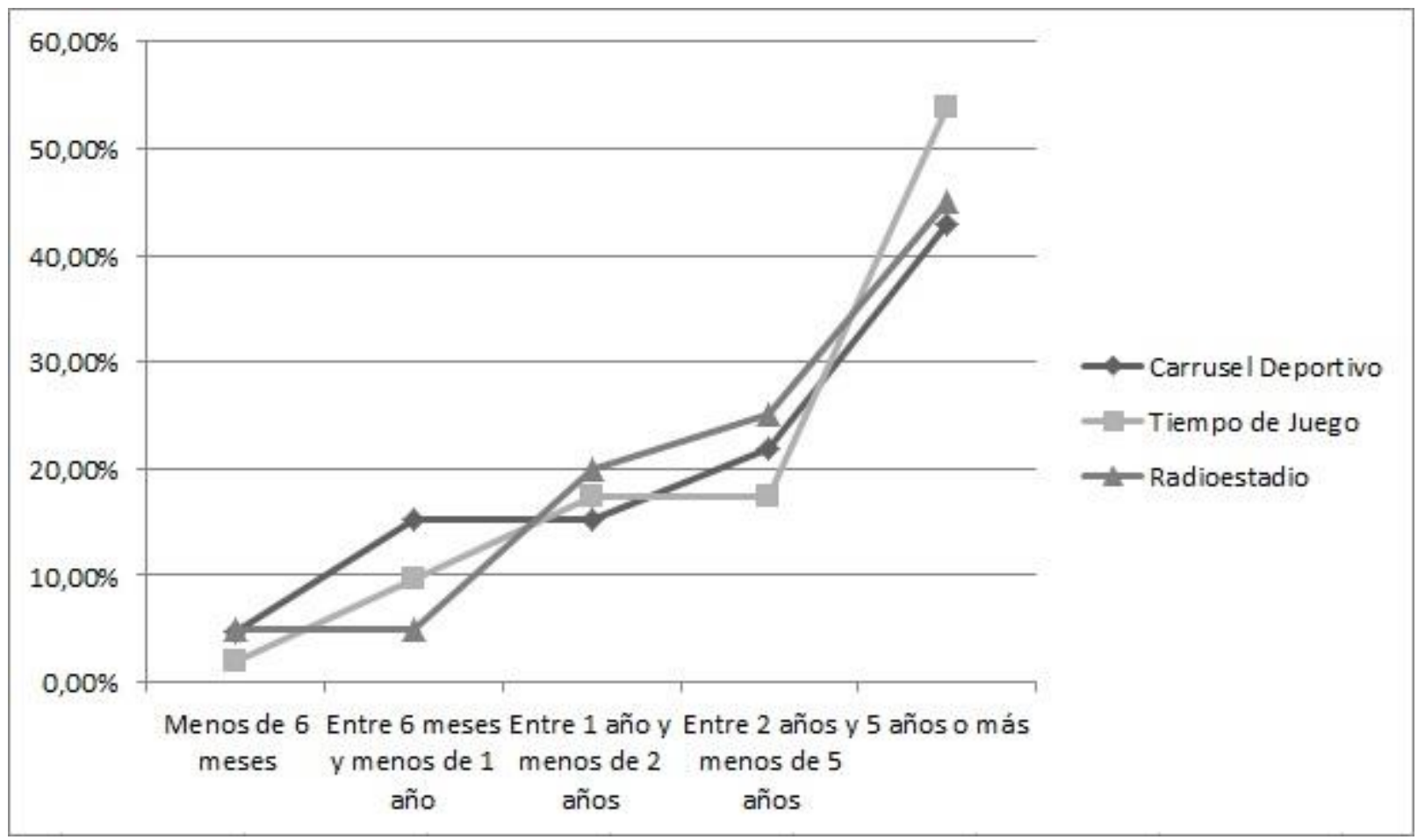

Fuente: Encuesta realizada por Gather Estudios para este estudio / Gráfico: elaboración propia.

En cuanto a la nota otorgada por los radioyentes castellanoleoneses a los respectivos programas (tercera de las hipótesis planteadas), de forma global obtienen una nota media de 7,16 puntos sobre 10. Por lo tanto, obtendría una puntuación bastante considerable. Como 
apunta algún autor, el oyente siempre ha tenido estima a la radio deportiva: "La radio y el deporte han sido siempre buenos compañeros. Los aficionados al deporte sienten en general una gran estima por este medio, que les ha informado de los éxitos deportivos de atletas y deportistas, que les ha hecho vibrar y emocionarse con el relato de los encuentros en los que participaba su club de toda la vida, que, en la actualidad, quizás les susurra polémicas deportivas a diario en la antesala del sueño" (Blanco, 2002: 22).

En lo que a la cuarta hipótesis respecta -cuáles son los motivos que llevan al radioyente de Castilla y León a escuchar un determinado programa y no otro- los datos muestran que las cinco principales respuestas obtenidas -las de mayor porcentaje- son las siguientes (hay que tener en cuenta que el encuestado podía escoger tantas respuestas como desease):

- Por los presentadores y locutores (frecuencia: 92; porcentaje: 46\%)

- Porque siempre he escuchado este programa y no me apetece cambiar (frecuencia: 78; porcentaje: $39 \%$ )

- Porque el programa que escucho me gusta más que los otros (frecuencia: 42; porcentaje: $21 \%)$

- Porque el programa que escucho me parece mejor que los otros (frecuencia: 35; porcentaje: $17,5 \%$ )

- Por todo el equipo que trabaja en esa emisora (frecuencia: 31; porcentaje: 15,5\%)

Dos de las cinco respuestas con más porcentaje -la primera y la quinta de las anterioreshacen alusión a los trabajadores de dicho programa. Especialmente la primera de las respuestas: el primer motivo sería el de los presentadores y locutores. Quizás, es importante especialmente la importancia de los locutores: "así como para presenciar un buen partido suele hacer falta que jueguen bien los veintidós jugadores y el árbitro, para oír un buen partido basta con que el locutor sea bueno" (Hernández, 1995: 234) y hasta el punto de que "en la mayoría de los ocasiones, al narrador deportivo se le hace responsable del éxito o del fracaso de audiencia de una retransmisión, cuando en realidad se trata de un producto diseñado y elaborado en equipo. El público, sin embargo, tienden a identificar al medio con la "voz" que narra el acontecimiento, de ahí que su papel sean tan comprometido" (Blanco, 2002: 27).

Otro de los motivos ("Porque siempre he escuchado este programa y no me apetece cambiar") obtiene su congruencia con la anterior hipótesis, en la que el mayor número de oyentes se concentraba en la franja de radioyentes que escuchaba dicho programa desde 
hacía 5 años o más (alta fidelización), algo que seguramente se va logrando con el paso del tiempo: "En una sola retransmisión es difícil ganar la confianza del oyente pero sí se puede empezar un duro camino" (Pons en Balsebre, 1999: 115). Otra de las opciones hace mera alusión a un motivo personal de gusto (gusta más uno que otro) y la opción cuarta se refiere a un motivo de percepción de calidad (un determinado programa es considerado mejor que los otros).

Por último, en lo que al medio de escucha del radioyente castellanoleonés de retransmisiones deportivas se refiere, predomina de forma general el sistema de escucha tradicional. En el 50\% de los casos, el canal de escucha es alguno de los siguientes:

- Transistor / aparato de radio / cadena / minicadena / similar

Otro gran porcentaje escucha este tipo de programas en el aparato de radio/música incorporado al coche. En menos del $10 \%$ se escoge la televisión/TDT. Según el estudio, son pocos los radioyentes que escogen medios de más reciente creación -como el teléfono móvil o Internet. Esto conduce a que aún siguen siendo los medios de escucha tradicionales los más empleados; quizás porque las emisoras radiofónicas "siguen sin dar el paso necesario para introducir todas las nuevas posibilidades comunicativas, que tanto en el plano formal como de contenido, pueden incorporar los profesionales de las respectivas emisoras con la digitalización del medio. Es por ello que apenas se hayan producido las transformaciones de lenguajes, contenidos, programas y programaciones que algunos expertos habían previsto en los últimos años" (, 2011: 150-151).

\section{Conclusiones}

Una vez obtenidos y discutidos los resultados, las conclusiones a las que se llega con esta investigación son las siguientes:

- La encuesta indica que el programa más escuchado de entre los cinco que forman parte de la muestra es «Carrusel Deportivo», de la Cadena SER, con más del 50\% de los oyentes, seguido por «Tiempo de Juego», de la COPE (26\%). Éstos serían los dos programas más escuchados por los radioyentes castellanoleoneses de retransmisiones deportivas de la radio generalista. Se corrobora la hipótesis 1.

- Los datos muestran una clara tendencia de fidelización de los radioyentes castellanoleoneses de los programas estudiados. En términos globales a los cinco programas, más del $45 \%$ de los oyentes siguen el programa en cuestión desde hace 5 
años o más. Y cuatro de los cinco programas concentran su mayor número de oyentes precisamente en la opción temporal de 5 años o más. Se acepta así la hipótesis 2.

- Según muestran los resultados, las notas otorgadas por los radioyentes castellanoleoneses de retransmisiones deportivas radiofónicas parecen satisfactorias. La nota media a todos ellos es de un 7,16 sobre 10 puntos. Además, ningún encuestado, fuera cual fuera el programa escuchado, señaló una nota inferior a 4 puntos. Dado que en la hipótesis planteada (número 3), se esperaba, al menos, una nota de 7, dicha hipótesis queda aceptada.

- En cuarto lugar, como se ha visto en el apartado correspondiente, varios son los motivos que llevan a los radioyentes encuestados en Castilla y León a escuchar un programa y no otro: por los presentadores y locutores que trabajan en el programa; porque un determinado oyente siempre ha escuchado un determinado programa y no le apetece cambiar; porque a un determinado oyente le gusta más el programa que escucha que los restantes; porque a un determinado oyente le parece mejor el programa que escucha que los restantes; o por la preferencia debido a todo el equipo que trabaja en dicha emisora que escucha. Por lo tanto, la hipótesis 4 -no existe una motivación concreta que permita determinar las causas por las que un radioyente escucha un programa y no otro- queda rechazada y se acepta la contraria: sí existe una motivación concreta que permita determinar las causas por las que un radioyente escucha un programa y no otro.

- Por último, en cuanto al medio de escucha, siguen siendo los medios tradicionales los más utilizados por el radioyente castellanoleonés de retransmisiones deportivas radiofónicas: transistor, aparato de radio, cadena, minicadena o similar $(50,3 \%)$ o aparato de música del coche $(31,7 \%)$, frente a los de más reciente aparición. Se acepta en parte la hipótesis 5 ya que se preveía la mayor concentración de respuestas en la primera opción -hecho que sí sucede- si bien otro gran porcentaje escogió la opción de "aparato de música del coche".

\section{Referencias bibliográficas}

AIMC: Resumen General del EGM: febrero a noviembre de 2011. Disponible en: http://www.aimc.es/spip.php?action=acceder document\&arg=1858\&cle=8b26d6f9b35f51a 8cb4bf06d70a86e0d\&file=pdf\%2Fresumegm311.pdf

ALCOBA, Antonio (2005): Periodismo deportivo. Madrid, Síntesis.

ALCOBA, Antonio (1993): Cómo hacer Periodismo deportivo. Madrid, Paraninfo.

BALSEBRE, Armand (1994): La credibilidad de la radio informativa. Barcelona, Feed-Back Ediciones. 
BLANCO, Josep María (2002): Las retransmisiones deportivas. Técnicas de narración radiofónica. Barcelona, CIMS.

CAGIGAL, José María (1981): Deporte: espectáculo y acción. Barcelona, Salvat.

CASTAÑÓN RODRÍGUEZ, Jesús (2004): Diccionario terminológico del deporte. Gijón, Ediciones TREA.

DÍAZ, Lorenzo (1992): La radio en España (1923-1993). Madrid, Alianza.

FAUS, Ángel (1974): La radio: introducción al estudio de un medio desconocido. Madrid, Guadiana de Publicaciones.

FórmulaTV.com / TVE (2012): "La 1, líder por tercer año consecutivo tras cerrar 2011 con una media del 14,5\%" (Lunes, 2 de enero de 2012) Disponible en: http://www.formulatv.com/noticias/22928/la1-lider-tercer-ano-consecutivo-tras-cerrar-2011encima-14-por-ciento/ [Fecha de consulta: 4 de febrero de 2012]

GOZALO, Juan Manuel (2002): “El periodismo deportivo en la radio". Cuadernos Hispanoamericanos, no 630, pp. 11-16. Consultado a través de: http://www.cervantesvirtual.com/obra/cuadernos-hispanoamericanos--62/

GUTIÉRREZ, María y HUERTAS BAILÉN, Amparo (2003): “La programación de las radios generalistas en España". ZER, número 15, noviembre de 2003, volumen 8, pp. 117-135. Disponible

en: https://docs.google.com/viewer?url=http\%3A\%2F\%2Fwww.ehu.es\%2Fzer\%2Fhemeroteca \%2Fpdfs\%2Fzer15-07-gutierrez.pdf

HERNÁNEZ ALONSO, Néstor (2003): El lenguaje de las crónicas deportivas. Madrid, Ediciones Cátedra.

HERNÁNDEZ CORONADO, Pablo (1955): Las cosas del fútbol. Madrid, Editorial Plenitud.

IGARTUA PEROSANZ, Juan José: Métodos cuantitativos de investigación en comunicación. Barcelona, Bosch.

MALVAR, Luis (2005): La radio deportiva en España (1927-2004). Madrid, Pearson Alhambra y Marca.

MEDINA, Federico (1995): "Los narradores deportivos y sus epopeyas cotidianas". Estudios sobre las culturas contemporáneas, vol. 1, no 002. México: Universidad de Colima, pp. 69106. Recuperado el 11 de enero de 2011 de: http://redalyc.uaemex.mx/redalyc/pdf/316/31600205.pdf

OLABE SÁNCHEZ, Fernando (2009): "La comunicación no convencional en los clubes de fútbol". Pensar la Publicidad, 2009, vol. III, no 1, pp. 121-138. ISSN: 1887-8598. Disponible en Internet http://revistas.ucm.es/index.php/PEPU/article/view/PEPU0909120121A/15348

en: 
ORTIZ SOBRINO, Miguel Ángel y CUESTA RICO, Juan: "Los contenidos informativos territoriales en las cadenas generalistas de radio: la imagen de Andalucía en el contexto informativo radiofónico español”. Comunicación y Hombre, número 5, 2009, pp. 145-166. ISSN: $\quad 1885-365 X$ Disponible en: https://docs.google.com/viewer?url=http\%3A\%2F\%2Fwww.comunicacionyhombre.com\%2 Fpdfs\%2F05 i ortizycuesta.pdf

PACHECO BARRIO, Manuel Antonio (2009): "La estructura actual de las retransmisiones futbolísticas en los programas de radio en España”. Ámbitos, número 18, 2009, pp. 99$114 . \quad$ Disponible en: https://docs.google.com/viewer?url=http\%3A\%2F\%2Fgrupo.us.es\%2Fgrehcco\%2Fambitos 18\%2F07pacheco.pdf

PERONA PÁEZ, Juan José (2009): “Información radiofónica y libros de estilo: análisis y propuestas de unos textos que claman renovación". Estudios sobre el Mensaje Periodístico, 2009, número 15, pp. 367-384. ISSN: 1134-1629. Disponible en: http://www.ucm.es/BUCM/revistas/inf/11341629/articulos/ESMP0909110367A.PDF

PONS, José Félix (1999): "El fútbol. Del receptor familiar al advenimiento del transistor", en BALSBRE, Armand (coordinación y redacción): En el aire: 75 años de Radio en España. Madrid, Promotora General de Revistas, pp. 115-123

RODERO ANTÓN, Emma (2005): Producción radiofónica. Madrid, Cátedra.

SALKIND, Neil J. (1998) [Traducción de Roberto L. Escalona; revisión técnica: Verónica Valdés Salmerón]: Métodos de investigación. México [etc.], Prentice Hall.

SIERRA SÁNCHEZ, Javier (2010): "Estudio de la oferta de programación de las radios autonómicas en España". Revista Latina de Comunicación Social, 65. La Laguna (Tenerife): Universidad de La Laguna, páginas 368 a 378 recuperado el 2 de febrero de 2011, de: http://www.revistalatinacs.org/10/art2/906 UAO/28 Sierra.html DOI: 10.4185/RLCS-65-2010-906-368-378

www.abc.es/radio/ [Página web de ABC Punto Radio]

www.aimc.es [Web de la Asociación para la Investigación de Medios de Comunicación desde la que se obtuvieron resúmenes del EGM (Estudio General de Medios)]

www.cadenaser.com [Página web de la cadena SER]

www.cope.es [Página web de la cadena COPE]

www.formulatv.com [Web de información sobre medios de comunicación desde la que se obtuvieron datos de audiencia a partir de datos de (c) Kantar Media]

www.frecuenciadigital.es [Web de información sobre los medios de comunicación desde la que se obtuvieron datos de audiencia de programas radiofónicos referidos a la tercera oleada del año 2011 del Estudio General de Medios (a través del link directo: http://www.frecuenciadigital.es/radio/egm/3-oleada-2011.html)] 
http://www.gatherestudios.es/ [Página web de Gather Estudios] www.introl.es [Página web de INTROL (Información y Control de Publicaciones)] www.ojd.es [Página web de la Oficina de Justificación de la Difusión, desde la que se obtuvieron datos de tirada y difusión de periódicos españoles]

www.ojdinteractiva.es [Página web de la OJDinterativa de la que se obtuvieron datos del seguimiento de WWW]

www.ondacero.es [Página web de Onda Cero]

www.puntoradio.com [Página web de Punto Radio]

www.rtve.es [Página web de RTVE]

\section{Forma de citar este artículo en bibliografías}

HERRERO, J. y ROMERO, H. J. (2014): El radioyente castellanoleonés de retransmisiones deportivas de la radio generalista. Estudio de cinco variables: sus preferencias, fidelización, satisfacción, motivaciones y medio de escucha, en Revista PANGEA, 5, páginas 40 a 63. Red Académica Iberoamericana de Comunicación. Recuperado el de de 2 de: http://www.revistapangea.org 